\title{
Strength characteristics of mink Mustela vison limb bones
}

\author{
James H. WILSON, Patrick F. SCANLON* and J. Philip MASON
}

Wilson J. H., Scanlon P. F. and Mason J. P. 1994. Strength characteristics of mink Mustela vison limb bones. Acta theriol. 39: 307-312.

The effects of sex and age of wild American mink Mustela vison Schreber, 1777 were investigated on four characteristics (thickness, cross-sectional area, shear force, and shear stress) of humeri and femurs. Thicknesses and cross-sectional areas were higher $(p<0.001)$ in males for both bones. Shear forces for both bones were higher $(p<0.01)$ in males. Age significantly $(p<0.07)$ affected shear stress of humeri. Increase in bone strength in males appears related to increase in bone thickness and cross-sectional area only and not to increases in shear stress. Bone geometry appears to respond to changes in body size while maintaining a constant or minimum value of shear-stress.

Department of Agricultural Engineering, Virginia Polytechnic Institute and State University, Blacksburg, Virginia 24061-0303, USA (JHW, JPM); Department of Fisheries and Wildlife Sciences, Virginia Polytechnic and State University, Blacksburg, Virginia 24061-0321, USA (PFS)

Key words: Mustela vison, bone strengths, mink

\section{Introduction}

Knowledge of the strength of wild animal bones is of interest from several points of view. Bone strength may allow determination of age and/or sex and may reflect the degree of contamination by such elements as lead and fluorine. Bone strength may be indicative of nutritional adequacy of wild animals or otherwise have forensic value. Knowledge of bone strength could be of value in designing or redesigning trapping, handling, and holding equipment for wild animals. The purpose of the present report is to examine the strength characteristics of bones of wild American mink Mustela vison Schreber, 1777 in relation to sex and age of the mink. Previous work (Wilson et al. 1984) provided data on mechanical properties of limb bones of river otters Lutra canadensis.

When investigating the strength of bones, many investigators have used the three-point bending test similar to that of Rowland et al. (1967). Other mechanical criteria used to test strengths of bone include tension, compression, shear, and torsion (Baker and Haugh 1979). These loading configurations allow mechanical properties such as tensile, compressive and shear stresses to be evaluated. Harner

\footnotetext{
* to whom the reprint requests should be sent
} 
and Wilson (1986) compared the three-point bending, shear, and torsion tests as means of evaluating bone strength in laying chickens Gallus domesticus. They concluded that the shear test worked best with all bones irrespective of bone geometry and circumvented the disadvantages of the other tests. Results indicated that the three-point bending test was good only when the bone was straight, had a symmetrical cross-section, and had a length-to-diameter ratio greater than 10 . The torsion test was useful only when the bone was straight and had a symmetrical cross-section. The main disadvantage of the tension and compression tests is that the bone samples must be machined to specific size and shape. The shear loading configuration (i.e. shear test) described by Wilson et al. (1984) was used in this investigation. The test measures shear force and shear stress can be determined by calculation (Wilson et al. 1984, Anonymous 1993).

\section{Materials and methods}

Mink were trapped during 2 successive legal trapping seasons in Virginia, USA by licensed trappers. Frozen carcasses $(n=283)$ were recovered from trappers and from registered fur buyers after each season. The sex of each was determined by visual inspection. The sample available was approximately $75 \%$ male which probably reflects differential vulnerability to trapping among the sexes.

The age of mink was determined using a systematic procedure described in Ogle (1984) and Ogle et al. (1989). Radiographs of canine teeth were used to evaluate the degree of closure of the pulp cavity and thus to segregate mink into young-of-the-year (1 yr.) and older mink. Second premolars from mink greater than 1 year were cleaned, sectioned, stained, and examined microscopically to identify cementum annuli which were used to designate the age in years. Among older mink, individuals aged 2 to 6 years old were identified. The great majority of mink were young-of-the-year which may reflect different trapping vulnerability of the age-groups, but almost certainly reflects the population structure.

Limbs were recovered from the mink carcasses and humeri and femors were dissected free of other tissues. The bones were retained in moist conditions. Humeri $(n=283)$ were available from both trapping seasons. Femurs $(n=81)$ were available from only one season. These bones were selected as representative long bones which are not fused with other long bones, and which would be less likely to be compromised in any way by trap action in mink trapped from the wild.

The cross-sectional areas of the humeri and femora were assumed to be similar to those of hollow ellipses. The exterior dimensions were taken at the center of the diaphysis before loading and an average wall thickness was derived from three measurements taken after the bone failure in the shear tests. The dimensions of each bone were measured with dial calipers having a precision of \pm $0.025 \mathrm{~mm}(0.001 \mathrm{in}$.). The area was calculated by:

$$
A=\frac{\pi}{4}\left[2\left(D_{1} t\right)+2\left(D_{2} t\right)-4 t^{2}\right]
$$

where: $D_{1}$ - major diameter (mm), $D_{2}$ - minor diameter $(\mathrm{mm})$, and $t$ - wall thickness $(\mathrm{mm})$.

The shear tests were performed using a double shear block apparatus (Wilson et al. 1984). The shear force was exerted over a $12.7 \mathrm{~mm}$ section located at the center of the diaphysis. These tests resulted in the ultimate shear force and shear stress being evaluated for each bone. The tests were conducted using an Instron Universal testing machine (Instron, Canton, Massachusetts, USA) at a loading rate of $5 \mathrm{~mm} / \mathrm{min}$. 
Shear forces and stresses were determined using the force-deformation curves from the tests and geometrical properties. The shear force-deformation curve provided the ultimate breaking load and the ultimate shear stress was then calculated. The ultimate shear stress is a function of shear force and cross-sectional area of the bone and was determined by:

$$
T=P /(A \times 2)
$$

where: $T$ - shear stress (MPa), $P$ - maximum shearing load (N), and $A \times 2$ - shear cross-sectional area $\left(\mathrm{mm}^{2}\right)$ for double shear.

Variables were examined using the GLM procedures of the Statistical Analysis System (SAS Institute Inc. 1985a, b). Differences between the two years in characteristics of humeri were not found and all data were pooled. Sex and age were used as factors in the GLM model. Mink 4 years old and older were treated as a single age group.

\section{Results and discussion}

Thicknesses of the bone wall of the humeri $(p<0.001)$ and femurs $(p<0.0002)$ were greater in males than in females (Table 1). Cross-sectional areas of both bones varied significantly $(p<0.0001)$ with sex (Table 2$)$. There were no significant interactions between age and sex for either bone.

The values for the maximum shear force and shear stress of the mink bones are given in Tables 3 and 4, respectively. The mean shear force of the humeri of males was significantly $(p<0.0001)$ higher than that of the females. A similar and significant $(p<0.002)$ trend was observed for the femur. The shear stress of the humeri did not differ by sex but differed significantly ( $p=0.066)$ with age. Shear stress of femurs was not influenced by sex or age but there was a significant $(p=0.05)$ sex-age interaction for the femur.

Shear stress is the ability of the intermolecular bonds of the bone material to resist deformation caused by an external load. The results of this investigation

Table 1. Mean ( $\pm \mathrm{SE}$ ) bone wall thickness $(\mathrm{mm})$ of mink bones by sex and age. ${ }^{\mathrm{a}}$ significant $(p<0.001)$ difference due to sex ${ }^{\mathrm{b}}$ significant $(p<0.0002)$ difference due to sex.

\begin{tabular}{|c|c|c|c|c|}
\hline \multirow{2}{*}{$\begin{array}{l}\text { Age } \\
\text { (yr) }\end{array}$} & \multicolumn{2}{|c|}{ Male } & \multicolumn{2}{|c|}{ Female } \\
\hline & $n$ & Mean $\pm \mathrm{SE}$ & $n$ & Mean \pm SE \\
\hline \multicolumn{5}{|c|}{ Humerus $^{a}$} \\
\hline 1 & 124 & $1.008 \pm 0.010$ & 48 & $0.833 \pm 0.023$ \\
\hline 2 & 38 & $1.069 \pm 0.155$ & 12 & $0.851 \pm 0.053$ \\
\hline 3 & 28 & $1.021 \pm 0.157$ & 6 & $0.950 \pm 0.041$ \\
\hline$\geq 4$ & 19 & $1.021 \pm 0.150$ & 5 & $0.866 \pm 0.109$ \\
\hline \multicolumn{5}{|c|}{ Femur ${ }^{b}$} \\
\hline 1 & 37 & $0.932 \pm 0.033$ & 12 & $0.747 \pm 0.406$ \\
\hline 2 & 7 & $0.940 \pm 0.079$ & 7 & $0.749 \pm 0.356$ \\
\hline 3 & 5 & $0.950 \pm 0.033$ & 4 & $0.858 \pm 0.406$ \\
\hline$\geq 4$ & 7 & $0.947 \pm 0.033$ & 2 & $0.635 \pm 0.025$ \\
\hline
\end{tabular}


Table 2. Mean $( \pm \mathrm{S}) \mathrm{E}$ cross-sectional area of bone $\left(\mathrm{mm}^{2}\right)$ of mink bones by sex and age). ${ }^{a}$ significant $(p<0.0001)$ difference due to sex, ${ }^{b}$ significant $(p<0.0001)$ difference due to sex.

\begin{tabular}{lrcrrr}
\hline \multirow{2}{*}{$\begin{array}{l}\text { Age } \\
\text { (yr) }\end{array}$} & \multicolumn{2}{c}{ Male } & & \multicolumn{2}{c}{ Female } \\
\cline { 2 - 3 } \cline { 5 - 6 } \cline { 5 - 6 } Humerus $^{\mathrm{a}}$ & $n$ & Mean $\pm \mathrm{SE}$ & & $n$ & Mean $\pm \mathrm{SE}$ \\
1 & & & & & \\
2 & 124 & $11.48 \pm 0.03$ & & 47 & $7.94 \pm 0.32$ \\
3 & 38 & $12.45 \pm 0.32$ & & 12 & $8.84 \pm 0.84$ \\
$\geq 4$ & 28 & $11.68 \pm 0.39$ & & 6 & $9.48 \pm 0.90$ \\
Femur & 19 & $12.00 \pm 0.52$ & & 5 & $8.06 \pm 1.42$ \\
1 & & & & \\
2 & 37 & $10.58 \pm 0.32$ & & 12 & $7.48 \pm 0.22$ \\
3 & 7 & $12.19 \pm 0.71$ & & 7 & $7.81 \pm 0.56$ \\
$\geq 4$ & 5 & $10.19 \pm 0.84$ & & 4 & $8.65 \pm 0.34$ \\
& 7 & $10.71 \pm 0.26$ & & 2 & $6.77 \pm 0.32$ \\
\hline
\end{tabular}

Table 3. Mean ( \pm SE) Shear Force (Newtons) of limb bones from mink by sex and age. ${ }^{\mathrm{a}}$ significant $(p<0.001)$ difference due to sex, ${ }^{\mathrm{b}}$ significant $(p<0.002)$ difference due to sex.

\begin{tabular}{|c|c|c|c|c|}
\hline \multirow{2}{*}{$\begin{array}{l}\text { Age } \\
\text { (yr) }\end{array}$} & \multicolumn{2}{|c|}{ Male } & \multicolumn{2}{|c|}{ Female } \\
\hline & $n$ & Mean $\pm \mathrm{SE}$ & $n$ & Mean $\pm \mathrm{SE}$ \\
\hline \multicolumn{5}{|c|}{ Humerus $^{a}$} \\
\hline 1 & 125 & $716 \pm 17$ & 48 & $554 \pm 33$ \\
\hline 2 & 38 & $783 \pm 43$ & 12 & $504 \pm 44$ \\
\hline 3 & 28 & $752 \pm 42$ & 6 & $492 \pm 61$ \\
\hline$\geq 4$ & 19 & $667 \pm 44$ & 5 & $398 \pm 82$ \\
\hline \multicolumn{5}{|c|}{ Femur $^{\mathrm{b}}$} \\
\hline 1 & 37 & $728 \pm 31$ & 12 & $540 \pm 45$ \\
\hline 2 & 7 & $761 \pm 93$ & 7 & $655 \pm 43$ \\
\hline 3 & 5 & $739 \pm 100$ & 4 & $449 \pm 97$ \\
\hline$\geq 4$ & 7 & $618 \pm 70$ & 2 & $445 \pm 200$ \\
\hline
\end{tabular}

have shown that the shear stress of the bones of both the males and females were essentially similar (Table 4) despite a significant difference between sexes in shear force (Table 3). Bone thicknesses and cross-sectional areas were significantly higher in males than in females. The indications are that bone geometry responds to increases in body size (weight) thereby increasing bone strength as measured by shear force while maintaining a constant (or minimum) value of stress in the bone. Statistical differences between males and females in the bone-breaking forces appear to relate to difference in bone wall thicknesses between males and 
Table 4. Mean ( \pm SE) Shear Stress (MPa) of limb bones from mink by sex and age. ${ }^{a}$ significant $(p=0.066)$ difference due to age, ${ }^{\mathrm{b}}$ significant $(p<0.05)$ sex by age interaction.

\begin{tabular}{lrrrrr}
\hline \multirow{2}{*}{$\begin{array}{l}\text { Age } \\
\text { (yr) }\end{array}$} & \multicolumn{2}{c}{ Male } & & \multicolumn{2}{c}{ Female } \\
\cline { 2 - 3 } \cline { 5 - 6 } & $n$ & Mean \pm SE & & $n$ & Mean \pm SE \\
\hline Humerus $^{\mathrm{a}}$ & & & & & \\
1 & 124 & $32.0 \pm 0.8$ & & 47 & $40.9 \pm 6.0$ \\
2 & 38 & $31.5 \pm 1.6$ & & 12 & $30.5 \pm 2.9$ \\
3 & 28 & $33.1 \pm 2.2$ & & 6 & $26.0 \pm 3.0$ \\
$\geq 4$ & 19 & $27.3 \pm 1.7$ & & 5 & $23.9 \pm 2.4$ \\
Femur & & & & & \\
1 & 37 & $34.8 \pm 1.5$ & & 12 & $37.2 \pm 2.9$ \\
2 & 7 & $31.8 \pm 4.4$ & & 7 & $42.6 \pm 2.0$ \\
3 & 5 & $37.7 \pm 4.2$ & & 4 & $26.1 \pm 5.5$ \\
$\geq 4$ & 7 & $28.9 \pm 3.4$ & & 2 & $32.2 \pm 13.2$ \\
\hline
\end{tabular}

females rather than to differences in shear stress. The overall mean shear stress was $30.7 \mathrm{MPa}$ for all humeri and $33.9 \mathrm{MPa}$ for the femurs. Yamada (1970) in his review noted that the shearing stress of compact bones of a limited range of animal species was greater in bones from the posterior limbs in comparison to those of the anterior limbs. Results presented in this report in regard to humeri and femurs of mink tend to support Yamada's observations.

Data on the effects of age on bone strength measurements of mink are more difficult to interpret given the present sample. A major problem was the preponderance of juvenile males in the sample and a scarcity of older animals. Age was not seen to significantly affect the thickness of humeri and femurs and the cross-sectional area though these tended to increase after the first year for both sexes and in both bones. Shear force for both bones tended to increase in males older than the first year but to decline in mink 4 years old and older. The pattern was less clear in females though the shear force was lowest in the oldest (4 years and older) mink. In considering shear stress, note again that cross sectional area was part of the denominator in the equation. A significant effect of age is apparent. Shear stress was lowest in humeri of mink 4 years and older. The pattern was less clear for shear stress of the smaller number of femurs examined as there was a significant sex-by-age interaction. Shear stress tended to vary differently among the age groups in the two sexes. It tended to increase in mink older than 1 year and ultimately decreased in mink 4 years and older. In river otters, shear stress tended to increase up to five years of age in the radii and ulnae but not in tibiae or fibulae (Wilson et al. 1984). While caution should be exercised in drawing conclusions from the relatively small number of river otters studied by Wilson et al. (1984), the indications from the present study are that some senescent characteristics of bones of mink are manifest by four years of age. 
Acknowledgements: The Virginia Commission of Game and Inland Fisheries funded a project which yielded the carcasses used in this study. Thanks to J. V. Gwynn, trappers and fur buyers for the supply of carcasses. M. C. Ogle provided age estimates of the mink used. M. B. Moss, S. E. P. Mersmann, L. A. Wilson, and J. P. Sullivan provided technical assistance.

\section{References}

Anonymous. 1993. Shear and three-point bending tests of animal bones. ASAE Standard No. S459. American Society Agricultural Engineers. St. Joseph, MO 40: 462-464.

Baker J. L. and Haugh C. G. 1979. Mechanical properties of bone: a review. Trans. Am. Soc. Agric. Eng. 22: 678-687.

Harner J. P. III and Wilson J. H. 1986. Testing techniques for determination of poultry bone strength. Trans. Am. Soc. Agric. Eng. 29: 642-644.

Ogle M. C. 1984. Heavy metal concentrations, aging techniques, and population characteristics of mink in Virginia with a review of the literature on delayed implantation in the mink. M. S. thesis, Virginia Polytechnic Institute and State University, Blacksburg, Virginia: 1-127.

Ogle M. C., Scanlon P. F., Clark A. G. and Gwynn J. V. 1989. A system for determining age of mink. Trans. Int. Union Game Biol. 19: 581-591.

Rowland L. O. Jr, Harms R. H., Wilson H. R., Ross I. J. and Fry J. L. 1967. Breaking strength of chick bones as an indication of dietary calcium and phosphorus adequacy, Proc. Soc. Exp. Bio. Med. 126: 399-401.

SAS Institute Inc. 1985a. SAS ${ }^{\mathrm{R}}$ User's Guide: Statistics, Version 5 Edition. SAS Institute Inc. Cary, NC: 1-956.

SAS Institute Inc. 1985b. SAS ${ }^{\mathrm{R}}$ User's Guide: Basics, Version 5 Edition. SAS Institute Inc. Cary, NC: 1-1290.

Wilson J. H., Anderson-Bledsoe K. L., Baker J. L. and Scanlon P. F. 1984. Mechanical properties of river otter limb bones. Zoo Bio. 3: 27-34.

Yamada H. 1970. Strength of biological materials. The Williams and Wilkins Company, Baltimore, MD: 1-297.

Received 18 September 1993, accepted 18 June 1994. 